\title{
Auditory Brainstem Implantation in Neurofibromatosis Type 2
}

DOI:

10.1097/MAO.0000000000001166

\section{Document Version}

Accepted author manuscript

Link to publication record in Manchester Research Explorer

\section{Citation for published version (APA):}

Ramsden, R. T., Freeman, S. R. M., Lloyd, S. K. W., King, A., Shi, X., Ward, C. L., Huson, S. M., Mawman, D. J., O'Driscoll, M. P., Evans, D. G., Rutherford, S. A., \& Manchester Neurofibromatosis Type 2 Service (2016).

Auditory Brainstem Implantation in Neurofibromatosis Type 2: Experience From the Manchester Programme.

Otology \& neurotology : official publication of the American Otological Society, American Neurotology Society [and]

European Academy of Otology and Neurotology. https://doi.org/10.1097/MAO.0000000000001166

\section{Published in:}

Otology \& neurotology : official publication of the American Otological Society, American Neurotology Society [and] European Academy of Otology and Neurotology

\section{Citing this paper}

Please note that where the full-text provided on Manchester Research Explorer is the Author Accepted Manuscript or Proof version this may differ from the final Published version. If citing, it is advised that you check and use the publisher's definitive version.

\section{General rights}

Copyright and moral rights for the publications made accessible in the Research Explorer are retained by the authors and/or other copyright owners and it is a condition of accessing publications that users recognise and abide by the legal requirements associated with these rights.

\section{Takedown policy}

If you believe that this document breaches copyright please refer to the University of Manchester's Takedown Procedures [http://man.ac.uk/04Y6Bo] or contact uml.scholarlycommunications@manchester.ac.uk providing relevant details, so we can investigate your claim.

\section{OPEN ACCESS}




\title{
Auditory Brainstem Implantation in Neurofibromatosis Type 2: Experience From the Manchester Programme
}

\author{
*Richard Thomas Ramsden, *Simon Richard Mackenzie Freeman, *\|
}

Simon Kingsley Wickham Lloyd, §₫Andrew Thomas King, \#Xin Shi, §Charlotte Lucy Ward, $\ddagger$ Susan Mary Huson, $†$ Deborah Jane Mawman, $\nmid$ Martin Paul O’Driscoll, $\ddagger$ Dafydd Gareth Evans, and $\S$ Scott Alexander Rutherford, on behalf of the Manchester Neurofibromatosis Type 2 Service

*Department of Otolarygology; †Department of Audiology; $\ddagger$ Manchester Centre for Genomic Medicine, Institute of Human Development, University of Manchester; and Central Manchester University Hospitals NHS Foundation Trust, Manchester Academic Health Science Centre, Manchester; §Department of Neurosurgery, Salford Royal Hospital NHS Foundation Trust, Salford; ||Institute of Cancer; IInstitute of Cardiovascular Sciences, University of Manchester, Manchester Academic Health Science Centre; and \#Business School, Manchester Metropolitan University, U.K

Objective: To describe the experience of auditory brainstem implantation (ABI) in patients with Neurofibromatosis type 2 (NF2).

Study Design: Retrospective case review.

Setting: Tertiary referral centre.

Patients: Implanted with a Cochlear ABI22 or ABI24M between 1994 and 2009 because of NF2 disease.

Intervention(s): Rehabilitative.

Main Outcome Measure(s): Surgical complication rate; audiological outcomes.

Results: There were 50 primary ABI insertions in 49 patients, including 16 inserted at the time of first side tumor removal as a sleeper, and two revision repositionings which failed to improve outcome. Postoperatively three patients had cerebrospinal fluid leaks which did not require reoperation, one patient had meningitis, and eight patients suffered either temporary or permanent lower cranial nerve dysfunction. Twenty-nine patients became full time users; a further 12 patients became non-users. Three patients died while their device was inactive. Five patients retain serviceable contralateral hearing. Audiological open set testing of users showed means of: environmental sounds discrimination $51 \%$; phoneme discrimination: with $\mathrm{ABI}$ alone $22 \%$ /lip reading (LR) 45\%/ABI with LR $65 \%$; sentence testing: with $\mathrm{ABI}$ alone 13\%/LR 19\%/ABI with LR 54\%.

Conclusions: The majority of patients with NF2 implanted with an $\mathrm{ABI}$ find the device a useful aid to communication in conjunction with LR and in recognizing common environmental sounds. A small proportion gain open set discrimination. Almost a third of patients may end up as non-users. There is probably an increased risk of postoperative lower cranial nerve dysfunction so careful preoperative assessment is advised. Key Words: Auditory brainstem implantBilateral deafness-Postoperative complications-SurgeryVestibular schwannoma.

Otol Neurotol 37:xxx-xxx, 2016.
The auditory brainstem implant (ABI) evolved from cochlear implant technology to rehabilitate those individuals with total bilateral deafness who are unsuitable for cochlear implantation because of non-functional cochlear nerves or unimplantable cochleas. The majority of candidates suffer from the genetic disorder neurofibromatosis type 2 (NF2) which causes bilateral vestibular schwannomas leading to deafness

QQ3 Address correspondence and reprint requests to Simon Richard Mackenzie Freeman, B.Sc. (Hons), M.Phil., F.R.C.S. (ORL-HNS), Department of Otolaryngology, Manchester Royal Infirmary, Oxford Road, Manchester, M13 9WL, U.K.;

E-mail: simon.freeman@cmft.nhs.uk

Source of Funding: None declared.

AQ4 The authors disclose no conflicts of interest.

DOI: 10.1097/MAO.0000000000001166 either by direct damage from the tumors themselves or from the surgery to remove them (1). The ABI stimulates the cochlear nucleus complex directly, which is readily accessible after vestibular schwannoma removal.

The Manchester programme participated in the original European pilot study (2), and since then has routinely offered it to appropriate patients. This article reviews our experience in NF2 patients.

\section{MATERIAL AND METHODS}

\section{Patients}

Patients were included in the study if they met the Manchester criteria for NF2 disease (3), and had been implanted with an ABI and had continued rehabilitation by the Manchester team between 1994 and 2009. 
Surgery and Intra-Operative Monitoring

The translabyrinthine approach was employed in 48 cases and the retrosigmoid in two cases. The operative technique is well described by other authors $(4,5)$. Facial and glossopharyngeal nerve monitoring were performed throughout the procedure. Intra-operative electrically evoked auditory brainstem responses (EABRs) were recorded from subdermal needle electrodes using a Medelec Synergy evoked potential system. For a detailed methodology for EABR recording and interpretation see O'Driscoll et al. (6).

\section{Rehabilitation}

Device activation took place 6 to 8 weeks after surgery. Electrodes producing unacceptable non-auditory sensations were excluded from the map. The number of electrodes producing an auditory only response was recorded.

\section{Data and Outcomes}

Data were collected from prospectively completed surgical and audiological databases. Data collected included patient demographics, previous history of surgery or stereotactic radiosurgery, surgical technique, complications, duration of preoperative profound hearing loss, and audiological outcomes.

Audiological outcomes included the following:

(1) The three alternative forced choice syllable test (3AFC; patients listen to a single word or a phrase and decide whether it is single or multisyllabic),

(2) The environmental sounds test (ES; open set test whereby patients try to identify common sounds such, as a door bell, out of a possible 20 different sounds).

(3) Phonemes correct in the Arthur Boothroyd (AB) monosyllabic words test with $\mathrm{ABI}$ alone, with lip reading (LR) alone and in combination (ABI+LR).

(4) Keywords correct in the City University of New York (CUNY) sentences test with ABI alone, with LR alone and in combination $(\mathrm{ABI}+\mathrm{LR})$.

In the majority of patients, best scores were achieved within 12 months. A small number of patients continued to improve with the device over several years. To take this into account, for the purposes of this study the best scores achieved were used, regardless of the time post-implantation.

Patients were categorized according to their ABI use. Categories included user, non-user, and sleeper. A sleeper is defined as a patient having $\mathrm{ABI}$ insertion at the time of surgical removal of their first vestibular schwannoma when there was still functional hearing in the contralateral ear. A number of sleepers have subsequently become users or non-users.

\section{Statistical Analysis}

Data were analyzed using the $\mathrm{R}$ statistical package (version 2.15). Both demographic variables (age at surgery; tumor size; primary versus revision surgery; duration of profound deafness in the implanted ear before surgery categorized into $<5$ years, $5-9$ years, $>10$ years) and ABI test variables (number of EABR peaks; number of auditory electrodes at device activation; user versus non-user; 3AFC; ES; CUNY ABI+LR; $\mathrm{AB} A B I+L R$ ) were analyzed descriptively to understand their distributions. Pearson correlation analysis was used to identify the associations of all variables with the intention of understanding the causal relationships among them. Variables were then taken into linear regression models to investigate their effects on $3 \mathrm{AFC}, \mathrm{ES}$, and CUNY ABI+LR $(p<0.05)$.
TABLE 1. Demographic details, preoperative tumor size and duration of deafness

\begin{tabular}{|c|c|c|}
\hline \multirow{2}{*}{$\begin{array}{l}\text { Gender } \\
\text { Age }\end{array}$} & \multicolumn{2}{|r|}{28 males; 21 females } \\
\hline & & Mean 29 yr; range $12-71$ yr \\
\hline \multirow[t]{7}{*}{ Tumor size } & & $\begin{array}{l}\text { Mean } 28 \mathrm{~mm} \text { maximum intracranial } \\
\text { diameter; }\end{array}$ \\
\hline & 2 & Tumor previously resected; \\
\hline & 3 & Intracanalicular; \\
\hline & 3 & $\begin{array}{l}<2 \mathrm{~cm} \text { maximum intracranial } \\
\text { diameter; }\end{array}$ \\
\hline & 16 & $\begin{array}{l}2-3 \mathrm{~cm} \text { maximum } \\
\text { intracranial diameter; }\end{array}$ \\
\hline & 17 & $\begin{array}{l}3-4 \mathrm{~cm} \text { maximum intracranial } \\
\text { diameter; }\end{array}$ \\
\hline & 12 & $\begin{array}{l}>4 \mathrm{~cm} \text { maximum intracranial } \\
\text { diameter }\end{array}$ \\
\hline Follow up & & Mean 8 yr; range $3-18$ yr \\
\hline \multirow{6}{*}{$\begin{array}{l}\text { Duration of profound } \\
\text { deafness in implanted ear }\end{array}$} & 17 & $<12 \mathrm{mo}$ \\
\hline & 3 & $12-24 \mathrm{mo}$ \\
\hline & 8 & $24-48 \mathrm{mo}$ \\
\hline & 2 & $4-6 \mathrm{yr}$ \\
\hline & 1 & $6-10 \mathrm{yr}$ \\
\hline & 4 & $10-20 \mathrm{yr}$ \\
\hline
\end{tabular}

${ }^{a}$ Includes only patients with auditory test scores.

\section{RESULTS}

The study population comprised of 49 individuals with 50 primary $\mathrm{ABI}$ insertions. There were six Cochlear ABI22 devices and 44 Cochlear ABI24M devices implanted. Demographic details are given in Table 1. Three patients had had previous radiosurgery on the ipsilateral side before ABI surgery (one device failed preactivation, one had no auditory electrodes, one had limited benefit (patient 10 in Figs. 1A, 2A, and 3A).

\section{Details of ABI Use}

Details of device use and auditory electrodes at activation are given in Table 2 .

\section{Sleepers}

In 16 instances, the ABI was inserted as a sleeper. All patients with sleeper ABIs were encouraged to practice with the device but compliance was generally poor. One sleeper suffered a device failure so a second ABI was implanted on the contralateral side. One patient uses the device in combination with a contralateral hearing aid in an ear with a severe hearing loss. Three patients have subsequently died while the ABI was "sleeping". Three patients have subsequently had their devices activated following removal of the contralateral tumor after a period of between 2 and 4 years and are active users.

Three patients had their devices activated but are now non-users; of these, one patient had four auditory electrodes at activation and initially became a user with limited benefit. Following ABI repositioning, he became a nonuser. The second patient (described in the "revision 

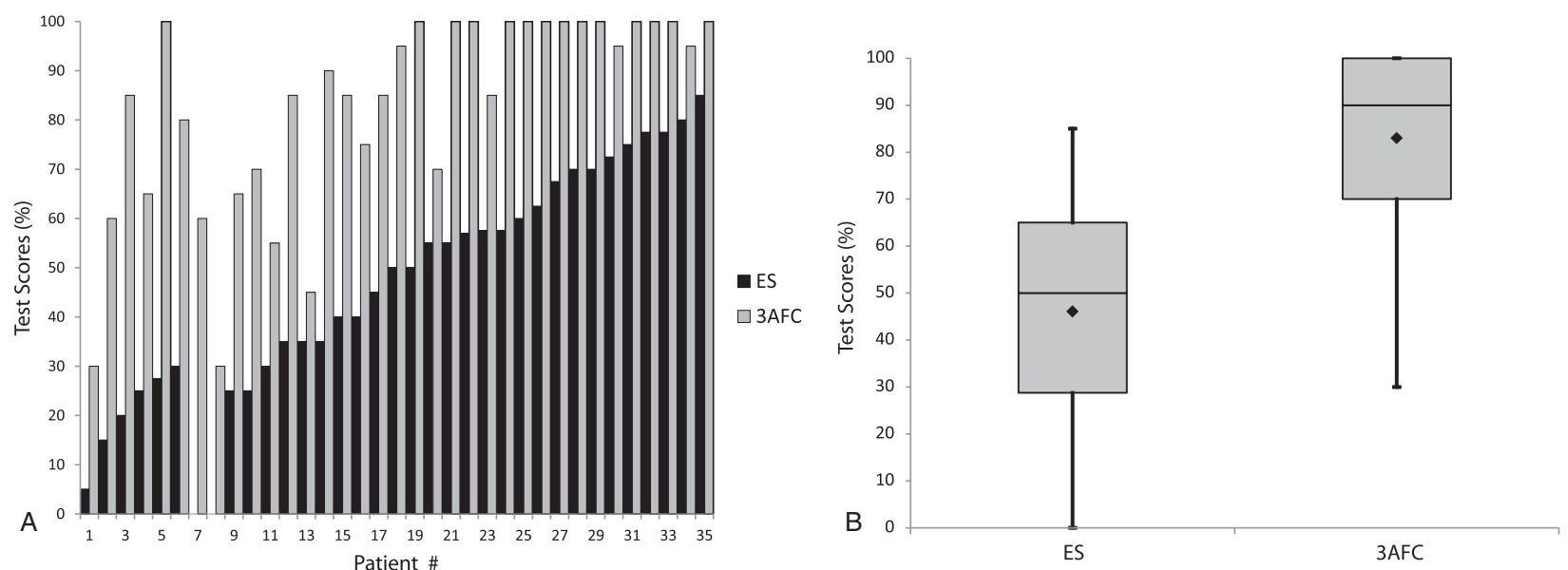

FIG. 1. A, Bar chart showing individual patient scores for the environmental sounds (ES) test and the three alternative forced choice (3AFC) test. Patients are numbered by $A B I$ non-use/use (with the first six being non-users) and then in consecutive order as per their scores in the ES test. B, Box and whisker plot showing patient scores for the ES test and the 3AFC test. Whiskers show the minimum and maximum values; median is shown by the solid line; mean is shown by the diamond.
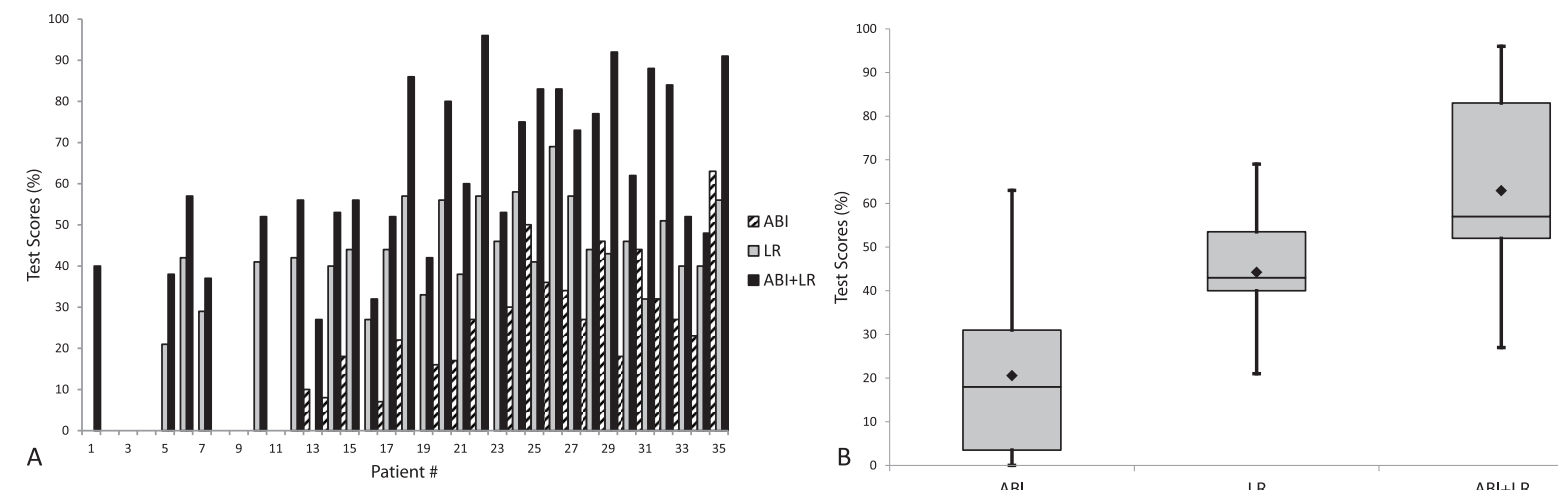

FIG. 2. A, Bar chart showing individual patient scores for the Arthur Boothroyd (AB) monosyllabic words test. Patients are numbered as per Figure $1 A$. B, Box and whisker plot showing patient scores for the $A B$ monosyllabic words test. Whiskers show the minimum and maximum values; median is shown by the solid line; mean is shown by the diamond. $A B I$ indicates sound only; $L R$, vision only; $A B I+L R$, sound and vision.
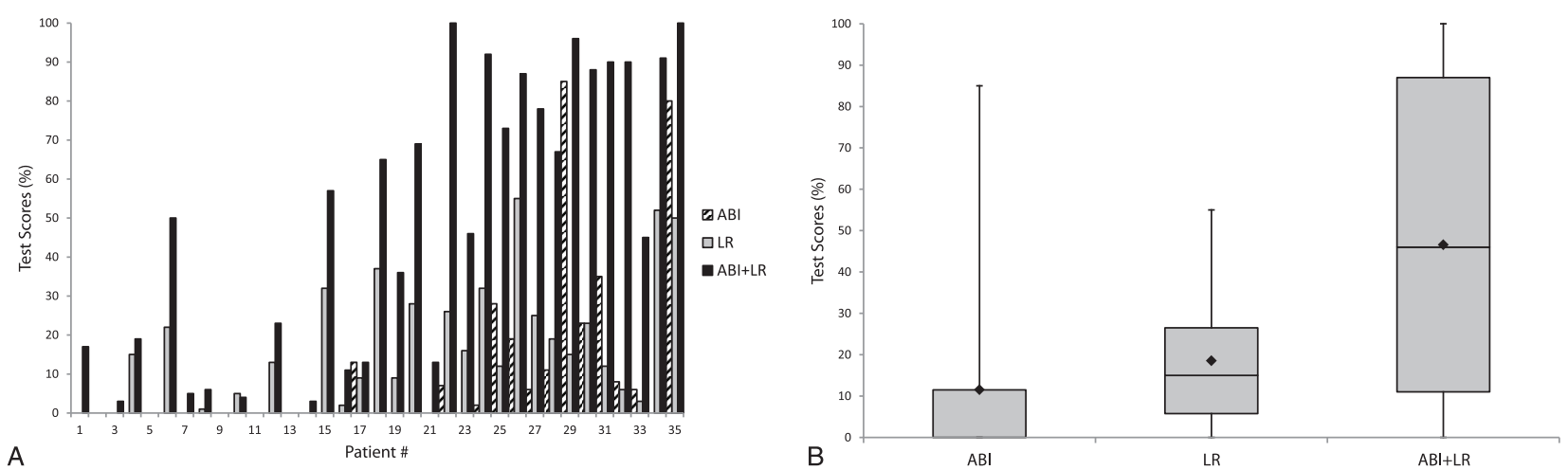

FIG. 3. $A$, Bar chart showing individual patient scores for the City University of New York (CUNY) sentences test. Patients are numbered as per Figure 1A. B, Box and whisker plot showing patient scores for the CUNY sentences test. Whiskers show the minimum and maximum values; median is shown by the solid line; mean is shown by the diamond. ABI indicates sound only; LR, vision only; $A B I+L R$, sound and vision. 
TABLE 2. Details of number of electrodes at device activation for different user groups

\begin{tabular}{ll}
\hline Activated Device Use $^{a}$ & Electrodes at Activation \\
\hline $\begin{array}{l}\text { Users }(\mathrm{n}=29, \text { includes four } \\
\text { activated sleepers })\end{array}$ & $\begin{array}{l}\text { Mean } 14 \text { auditory } \\
\text { electrodes; range 6-21 }\end{array}$ \\
$\begin{array}{l}\text { Non-users with } \\
\text { no audition }(\mathrm{n}=4)\end{array}$ & 0 \\
Elective non-users $(\mathrm{n}=5)$ & $\begin{array}{l}4,4,8,18,18 \text { auditory } \\
\text { electrodes, respectively } \\
\end{array}$ \\
Activated sleeper non-users $(\mathrm{n}=3)$ & $3,4,9$ \\
\hline
\end{tabular}

${ }^{a}$ Excludes sleepers if the patient still has functional contralateral hearing or died with functional contralateral hearing.

surgery", section below) had nine auditory electrodes initially but this deteriorated to one by the time of contralateral surgery. He elected not to have a contralateral ABI inserted. The third had three auditory electrodes with poor benefit and elected not to use the device.

Three patients with longstanding sleeper ABIs have had the magnets removed to facilitate magnetic resonance imaging (MRI). It is now our policy to remove the magnet at the time of insertion for sleeper ABIs, if possible.

\section{Surgical Complications}

Facial nerve complications are not detailed as these are principally related to tumor size and difficulty of resection. Cerebrospinal fluid (CSF) leaks occurred in three patients through the skin wound and were all successfully managed with additional skin sutures. One patient developed meningitis and recovered without further complications. One patient suffered a single postoperative seizure. Two patients developed temporary palsies of the trigeminal and abducens nerves, respectively.

Eleven patients suffered lower cranial nerve dysfunction. One patient had a small $(1 \mathrm{~cm})$ tumor with a concomitant 9th nerve tumor that required significant mobilization to access the foramen of Luschka. Seven patients suffered permanent vocal cord palsy and one also had temporary contralateral vocal cord palsy and required a temporary tracheostomy; five of these patients required nasogastric (NG) feeding for up to 6 weeks. One patient had temporary vocal cord palsy. A further three patients required NG feeding for up to 4 weeks.

\section{Revision Surgery}

Two patients have had further ipsilateral surgery to remove residual tumor with the $\mathrm{ABI}$ in situ. In both cases the ABI function remained unchanged postoperatively. In one case total removal was achieved but in the second, near-total was performed to protect the facial nerve. This tumor rapidly regrew and needed further surgery. Because of the aggressive tumor growth, poor preoperative facial and lower cranial nerve function and poor ABI function (only four auditory electrodes), a planned total removal was conducted with sacrifice of the facial nerve and repositioning of the ABI. Unfortunately, despite reasonable intraoperative EABR recordings,
TABLE 3. Audiological outcomes

\begin{tabular}{|c|c|c|}
\hline Intraoperative EABR & 1 & $\begin{array}{l}\text { Not recordable due } \\
\text { to equipment failure }\end{array}$ \\
\hline & 1 & No response \\
\hline & 12 & One peak \\
\hline & 22 & Two peaks \\
\hline & 10 & Three peaks \\
\hline & 4 & Four peaks \\
\hline $3 \mathrm{AFC}$ & $\begin{array}{l}\text { Mean } 83 \% \text {; median } 90 \% \text {; } \\
\text { range } 30-100 \%\end{array}$ & \\
\hline ES & $\begin{array}{l}\text { Mean } 46 \% \text {; median } 50 \% \text {; } \\
\text { range } 0-85 \%\end{array}$ & \\
\hline $\mathrm{AB} \mathrm{ABI}$ & $\begin{array}{l}\text { Mean } 21 \% \text {; median } 18 \% \text {; } \\
\text { range } 0-63 \%\end{array}$ & \\
\hline AB LR & $\begin{array}{l}\text { Mean } 44 \% \text {; median } 43 \% \text {; } \\
\text { range } 21-69 \%\end{array}$ & \\
\hline $\mathrm{AB} \mathrm{ABI}+\mathrm{LR}$ & $\begin{array}{l}\text { Mean } 63 \% \text {; median } 57 \% \text {; } \\
\text { range } 27-96 \%\end{array}$ & \\
\hline
\end{tabular}

3AFC indicates three alternative forced choice test; AB, Arthur Boothroyd monosyllabic words test; ABI, sound only; ABI+LR, sound and vision; CUNY, City University of New York sentences test; EABR, electrically evoked auditory brainstem response test; ES, environmental sounds test; LR, vision only.

there was only one functioning auditory electrode and this patient is now a non-user. A contralateral ABI was thought to be inadvisable because of the risk of causing damage to the lower cranial nerves on the second side.

One patient had repositioning of the ABI electrode array as she had no auditory electrodes and a computed tomography (CT) scan showed the electrode array had slipped out of the foramen of Luschka. Following this, the ABI remained non-functional and the patient had a temporary vocal cord palsy and required NG feeding for 6 weeks. In both cases where the electrode array was subsequently repositioned, there was dense scarring around the array and a combination of blunt and sharp dissection was required to mobilize it.

\section{Non-Auditory Stimulation}

All patients except one experienced non-auditory effects of stimulation on at least one electrode. The most common reported side effect was perstimulatory dizziness in $55 \%$ of cases and of those there was observable nystagmus or ocular deviation in a third. Other reported or observed effects included facial twitching and sensory change in the throat and in the limbs and trunk.

\section{Intraoperative EABR and Audiological Outcome Data}

Intraoperative EABR and audiological outcome data are given in Table 3 and Figures $1-3$. Word and sentence scores were not always available as one patient could not speak English, and seven could not be fully tested.

Figure 1 demonstrates that most patients can perform $3 \mathrm{AFC}$ relatively well but there is a wide range of results with regard to environmental sound discrimination. Nonusers did not score more than $30 \%$ on ES. Figures 2 and 3 demonstrate that the majority of patients with the ABI alone achieve some phoneme discrimination on $\mathrm{AB}$ word 
scores but perform poorly on CUNY sentence discrimination, with only two patients gaining more than $40 \%$ open set discrimination and a further three scoring between 20 and $40 \%$. Most receive a reasonable gain when the ABI is combined with LR.

\section{Prognostic Factors}

Pearson correlation analysis was conducted with the significant level 0.05 . The outcomes of Kendall's tau-b and Spearman tests were consistent with Pearson tests at the same significant level. This analysis found:

1) There was no significant difference between activated sleepers or non-sleepers on any audiological outcome $(p>0.5)$.

2) There was no significant differences in tumor size, age at surgery, and previous surgery on any ABI test variable $(p>0.5)$.

3) Duration of hearing loss correlated with $\mathrm{AB}$ $\mathrm{ABI}+\mathrm{LR}(p<0.01)$ but not with any other ABI test variable.

4) The number of auditory electrodes at device activation correlated weakly with CUNY $\mathrm{ABI}+\mathrm{LR}$ $(p=0.04)$ but not with any other ABI test variable.

5) The number of EABR peaks correlated strongly with $\mathrm{ES} \quad(p<0.01)$ and $\mathrm{CUNY} \quad \mathrm{ABI}+\mathrm{LR}$ $(p=0.01)$ and weakly with $3 \mathrm{AFC}(p=0.03)$ but not with $\mathrm{AB} A B I+L R$ or use/non-use.

6) Users gained higher scores in $\operatorname{ES}(p<0.01)$, and CUNY ABI+LR $(p=0.02)$ compared with nonusers but not $3 \mathrm{AFC}$ or $\mathrm{AB} \mathrm{ABI}+\mathrm{LR}$.

7) ES, 3AFC, and CUNY ABI+LR are highly and positively associated with each other $(p<0.01)$.

Looking at the association and size of the effects between test variables (3AFC, ES, and CUNY ABI+LR) LR) and other factors (age at surgery, tumor size, previous surgery, duration of profound deafness, number of EABR peaks, number of auditory electrodes at device activation and user/non-user) linear regression analysis showed that all three test scores were significantly associated with number of EABR peaks $(p<0.05)$. ES was also significantly associated with use. CUNY $\mathrm{ABI}+\mathrm{LR}$ was weakly associated with use, but only with EABR peaks and number of electrodes in the best model.

\section{DISCUSSION}

Excluding those with residual hearing on the contralateral side, approximately $70 \%$ of individuals in this study were users of their implants. The majority were able to recognize the prosodic patterns of speech and to identify environmental sounds. Most ABI users gained enhanced communication skills when combined with LR to an extent that was greater than the sum of the two individual skills. Subjectively these abilities are of value $(7,8)$. In only a very small number of individuals was performance with the ABI comparable to that expected from a cochlear implant, most of whom achieve open-set speech understanding and high sentence scores even in NF2 (9). While these results are comparable to the majority of studies evaluating the ABI5 (4,5,9-14), some recent publications have demonstrated a greater proportion of high performing users (15-18). Explaining the discrepancy between outstanding results and limited audition remains the biggest challenge for teams working with the ABI.

\section{Preoperative Factors as Prognostic Indicators}

Colletti et al. (18) first reported a group of non-tumor non-NF2 ABI patients with a greater than expected proportion of open-set speech discrimination through the ABI alone compared with their NF2 cohort. They surmised that the effects of preoperative tumor size and surgical removal caused deleterious effects to the cochlear nucleus. More recently Matthies et al. $(15,16)$, and Behr et al. (17), have demonstrated similar outcomes with NF2 patients as well, finding that tumor size did not affect their results. The two outstanding patients in our series had large tumors with brain stem compression; the best was in a young man presenting with two $4 \mathrm{~cm}$ tumors. By way of contrast some very small tumors with no compression of the stem were associated with poor results. Statistically, there was no association of tumor size with any auditory outcome.

Matthies et al. (15), found that duration of deafness was important, with all outstanding users having been deaf in their implanted ear for less than 24 months. Our two outstanding users had also both been deaf for less than 24 months. The correlation of duration of deafness with $\mathrm{AB} A B I+L R$ phoneme scores in our study suggests an association but with such small numbers in the longer duration of deafness groups, conclusions are uncertain.

Previous stereotactic radiosurgery could have a deleterious effect. While we found poor performance in the two activated cases others $(10)$, found three patients all derived good benefit.

\section{Surgical Factors as Prognostic Indicators}

It is recognized that the tonotopic arrangement within the cochlear nucleus is less favorable than that in the cochlea, where spectral analysis is relatively precise. In the cochlear nucleus the tonotopic arrangement is less well defined and is disposed in three dimensions with frequency maps altering with the distance from the surface of the nucleus. Single photon emission tomography studies of the auditory cortex in an NF2 ABI user found that although high frequencies were well represented in the cortex, low frequencies were relatively poorly projected (19). In practice pitch ranking often occurs in a random fashion rather than as might be expected from the tonotopic arrangement (20). In theory electrodes that could penetrate the nucleus to varying depths might improve access to different frequency areas of the nucleus. In practice, experience of a penetrating ABI has not conferred any obvious benefit over the conventional surface electrode array (21). Possibly the benefits of improved tonotopicity were 
outweighed by damage to the cochlear nucleus by the penetrating array.

Subtle anatomic variations in the relationship between the cochlear nucleus and the foramen of Luschka, which may be further distorted by compression from a large tumor mass, might affect ideal positioning of the array (22). Matthies et al. (15), used the stimulating device that comes with the MED-EL ABI to perform intraoperative preplacement EABR. This device is the same size as the ABI electrode array, which is significantly smaller than that of its counterpart from Cochlear. It also has no Dacron mesh so it is easy to move around atraumatically. Matthies et al. (23), suggested that mapping the area of the cochlear nucleus may have been one of the factors that lead to their exceptional results. As we used the Cochlear ABI, we did not have the benefit of this device, so used the ABI array itself to perform EABR (25). We found the quality of the intraoperative EABR, as determined by the number of peaks, to be significantly associated with better outcomes but when we tried to move it to map the area we often found the signal deteriorated leading us to conclude that trauma to the cochlear nucleus may be occurring.

It is thought that so called "chopper neurons" in the nucleus confer the ability to distinguish very tiny modulations in amplitude of the signal, and the loss of or damage to these cells could impair the ability to disAQ6 criminate speech (26). The presence of a large tumor mass may have a damaging effect on the cells of the nucleus as may surgical manipulation or bipolar diathermy, with either direct thermal damage or ischaemia secondary to interruption of the blood supply to the nucleus. Behr et al. (17) and Matthies et al. (23), both stated that they try their utmost to avoid all bipolar cautery during tumor removal. This is supported by use of the semi-sitting position which they found to have a significant association with open-set discrimination. This position is rarely used in the United Kingdom and we think the uncertain possibility of improved results does not justify the increased intraoperative risk of air embolism.

\section{Device Factors as Prognostic Indicators}

As discussed above, the larger size of the Cochlear ABI array compared with the MED-EL ABI may be a factor during surgery as it requires more dissection to insert. It also has a larger Dacron mesh attached, which is designed to cause a fibrotic reaction to fix the electrode in place. While this may lead to less likelihood of displacement, the greater fibrotic reaction could be traumatic to the cochlear nucleus.

One might think that the larger electrode paddle of the

AQ7 Cochlear device, with its increased number of electrodes, may give a better likelihood of covering the appropriate neurons of the cochlear nucleus. However, the larger size may simply lead to increased non-auditory stimulation, one of the major factors in determining outcome. Matthies et al. (16), only deactivated a mean 2 out of 12 electrodes in users compared with 7 out of 21 in our cohort. Indeed, the correlation we found between number of electrodes at switch on and CUNY ABI+LR suggests that this directly impacts on the patients' ability to communicate. However, it may alternatively reflect that a critical number of electrodes are needed for effective communication and environmental discrimination, as all our users had at least six auditory electrodes. This is in keeping with the findings of others; Otto et al. (21), found with the eight channel Cochlear ABI that those with less than three electrodes were non-users and those with six to eight performed much better. Matthies et al. (16), found all users had at least five auditory electrodes and Grayeli et al. (10), using the 21 channel Cochlear ABI, observed all their best users had at least 10 electrodes and others had at least 4. Behr et al. (17), while describing the group of exceptional performers, found that it was the number of electrodes that provided distinct pitch discrimination that was important.

\section{Surgical Complications}

Surgical complications appeared no more frequent than those expected from tumor removal alone, except for lower cranial nerve injury. While these nerves require mobilization and are at risk from vestibular schwannoma removal, particularly with larger tumors, we noted a much higher incidence of postoperative dysphagia and vocal cord palsy than we would have expected. The literature is divided on this issue. Schwartz et al. (5), noted "a far higher incidence of aspiration and dysphagia" following ABI insertion and Sanna et al. (14), shared this experience. Matthies et al. (15), found 4 of 18 patients had worse lower cranial nerve function postoperatively. Others have not noted an increased incidence $(4,9,27)$.

As well as the usual manipulation required to remove the tumor, these patients have additional risk factors for lower cranial nerve palsy. The glossopharyngeal nerve often requires further mobilization to access the foramen of Luschka and may be in close proximity to the electrode array. The lower cranial nerves may also have schwannoma formation. Not only does this predispose the nerves to dysfunction but more robust manipulation may be required to access the foramen, putting further strain on the nerves. We recommend careful assessment of laryngeal function to exclude a preoperative contralateral palsy that could result in a bilateral lower nerve deficit following surgery.

\section{Revision Surgery}

Revision surgery was required in several circumstances. Where a patient had undergone previous tumor resection, placing the $\mathrm{ABI}$ was no more difficult than usual. Where we were removing further tumor without the need to move the ABI, although great care was required not to damage the electrode array, we found this to be straight-forward, particularly where we were able to alter the surgical approach from translabyrinthine to retrosigmoid. Our limited experience of attempting to remove and reposition an electrode array that had 
seemingly moved following the original surgery was not encouraging. In each case there was an extensive fibrotic reaction, including a third non-NF2 case not reported here, with either no improvement or worsening of function. Discussion with colleagues at other centers has suggested similar experiences with revision surgery for the Cochlear device (MS Schwartz, DE Brackmann, M Kalamarides, O Sterkers, R Behr, personal communications) but less so for the MED-EL device where successful revisions have been reported $(9,15)$. We surmise this relates to the size of both the array and the Dacron mesh.

\section{Use of Sleepers}

In this series, we have adopted the policy of offering an $\mathrm{ABI}$ to patients at their first tumor removal even in the presence of useful or aidable hearing in the contralateral ear. The reason for inserting these "sleepers" was to allow two possible "bites at the cherry". If difficulty was encountered inserting the sleeper, the attempt was abandoned rather than risk damage to the brainstem. These sleepers have lain dormant for up to 13 years and so far only 3 out of 16 have been activated. Three more patients have died before their sleeper could be activated. During the period of "sleep" we have encouraged the patients to activate the device at regular intervals although most patients found this too difficult while they still had reasonable contralateral hearing. It could be argued that in financial terms our approach has been extravagant and perhaps it should be re-examined in light of information that is beginning to emerge on the slow progression of hearing loss in NF2 and the increased use of both bevacizumab and cochlear implants. Nevertheless, with only seven out of $10 \mathrm{ABIs}$ providing auditory benefit, the potential for a second chance seems a reasonable proposition. Currently, we counsel patients carefully before first sided tumor removal as to the pros and cons of sleeper insertion, taking particular account of their motivation, psychological status, social support, general well-being and comorbidities, the size and growth rate of the contralateral tumor, the contralateral hearing, and the effect on future MRI.

AQ10 Acknowledgments: Members of the Manchester Neurofibromatosis Type 2 Service:

Genetics: D Gareth Evans, Susan Huson.

Radiology: Owen Thomas, Gillian Potter, Roger Laitt, Stavros Stivaros.

Neurology: Mark Kellett, Grace Vassallo, John Ealing.

Neurosurgery: Scott Rutherford, Andrew King, Charlotte Ward, Ian Kamaly, Conor Mallucci.

Otolaryngology: Simon R Freeman, Simon Lloyd.

Audiology: Deborah Mawman, Martin O’Driscoll.

Oncology: John-Paul Kilday, Martin McCabe, Catherine McBain.

Nursing: Raji Anup, Mary Perry, Nicola Jarvis, Patricia Braithwaite.

Plastic surgery: Chris Duff, David Mowatt.

Ophthalmology: Eva Gajdosova, Ahmed Sadiq.
Physiotherapy: Lisa Fitzgerald.

Data Manager: Vilka Scott-Kitching.

Clinical Psychology: Sonia Patel.

\section{REFERENCES}

1. Evans DGR, Lloyd SKW, Ramsden RT. Neurofibromatosis type 2 Adv Otorhinolaryngol 2011;70:91-8.

2. Nevison B, Laszig R, Sollmann WP, et al. Results from a European clinical investigation of the nucleus multichannel auditory brainstem implant. Ear Hear 2002;23:170-83.

3. Baser ME, Friedman JM, Wallace AJ, et al. Evaluation of clinical diagnostic criteria for neurofibromatosis 2. Neurology 2002;59:1759-65.

4. Kanowitz SJ, Shapiro WH, Golfinos JG, et al. Auditory brainstem implantation in patients with neurofibromatosis type 2. Laryngoscope 2004; 1145:2135-46.

5. Schwartz MS, Otto SR, Shannon RV, et al. Auditory brainstem implants. Neurotherapeutics 2008:5:128-36.

6. O’Driscoll M, El-Deredy W, Ramsden RT. Brain stem responses evoked by stimulation of the mature cochlear nucleus with an auditory brain stem implant. Ear Hear 2011;32:286-99.

7. McSorley A, Freeman SRM, Ramsden RT, et al. The subjective outcome of auditory brainstem implantation. Otol Neurotol 2015;36:873-8

8. Lloyd SK, Glynn FJ, Rutherford SA, et al. Ipsilateral cochlear implantation after cochlear nerve preserving vestibular schwannoma surgery in patients with neurofibromatosis type 2. Otol Neurotol 2014;35:43-51.

9. Behr R, Müller J, Shehata-Dieler W, et al. The high rate CIS auditory brainstem implant for restoration of hearing in NF-2 patients. Skull Base 2007;17:91-107.

10. Grayeli AB, Kalamarides M, Bouccara D, et al. Auditory brainstem implant in neurofibromatosis type 2 and non-neurofibromatosis type 2 patients. Otol Neurotol 2008;29:1140-6.

11. Lenarz T, Moshrefi M, Matthies C. Auditory brainstem implant:auditory performance and evolution over time. Otol Neurotol 2001;22:823-33

12. Maini S, Cohen MA, Hollow R, et al. Update on long-term results with auditory brainstem implants in NF2 patients. Cochlear Implants Int 2009;10:33-7.

13. Otto SR, Brackmann DE, Hitselberger WE, et al. Multichannel auditory brainstem implant: update on performance in 61 patients. $J$ Neurosurg 2002;96:1063-71.

14. Sanna M, Di Lella F, Guida M, et al. Auditory brainstem implants in NF2 patients: results and review of the literature. Otol Neurotol 2012;33:154-64

15. Matthies C, Brill S, Varallyay C, et al. Auditory brainstem implants in neurofibromatosis Type 2: is open speech perception feasible? $J$ Neurosurg 2014;120:546-58

16. Matthies C, Brill S, Kaga K, et al. Auditory brainstem implantation improves speech recognition in neurofibromatosis type II patients. ORL J Otorhinolaryngol Relat Spec 2013; 75:282-95.

17. Behr R, Colletti V, Matthies C, et al. New outcomes with auditory brainstem implants in NF2 patients. Otol Neurotol 2014;35:184451.

18. Colletti V, Shannon R, Carner M, et al. Outcomes in nontumor adults fitted with the auditory brainstem implant: 10 years' experience. Otol Neurotol 2009;30:614-8.

19. Di Nardo W, Picciotti P, Di Giuda S, et al. SPET assessment of auditory cortex stimulation and tonotopic spatial distribution in auditory brainstem implant. Acta Otorhinolaryngol Ital 2004; $24: 321-5$.

20. McKay CM, Azadpour M, Jayewardene-Aston D, et al. Electrode selection and speech understanding in patients with auditory brainstem implants. Ear Hear 2015;36:454-63. [Epub AQ14 thead of print?

21. Otto SR, Shannon RV, Wilkinson EP, et al. Audiologic outcomes with the penetrating electrode auditory brainstem implant. Otol Neurotol 2008;29:1147-54. 
22. Rosahl SK, Rosahl S. No easy target: anatomic constraints of electrodes interfacing the human cochlear nucleus. Neurosurgery 2013;72:58-64. discussion 65 .

23. Matthies C, Brill S, Shehata-Dieler W. Response. J Neurosurg 2014;120:544-5.

24. Nevison B. A guide to positioning of brainstem implants using intra-operative electrical auditory brainstem responses. Adv Otorhinolaryngol 2006;64:154-66.

25. Kuchta JU, Otto S, Shannon RV, et al. The multichannel auditory brainstem implant: how many channels make sense? J Neurosurg 2004;100:16-23.
26. Bahmer A, Langner G. Oscillating neurons in the cochlear nucleus: 1. Experimental basis of a stimulation paradigm. Biol Cybernetics 2006;95:371-9.

27. Colletti V, Shannon RV, Carner M, et al. Complications in auditory brainstem implant surgery in adults and children. Otol Neurotol 2010;31:558-64.

\section{Uncited references}

(24).

AQ9 


\section{MAO}

Manuscript No. -15-391

\section{Otology \& Neurotology}

Dear Author,

During the preparation of your manuscript for typesetting, some queries have arisen. These are listed below. Please check your typeset proof carefully and mark any corrections in the margin as neatly as possible or compile them as a separate list. This form should then be returned with your marked proof/ list of corrections to the Production Editor.

\section{QUERIES: to be answered by AUTHOR}

\begin{tabular}{|c|c|c|}
\hline QUERY NO. & QUERY DETAILS & RESPONSE \\
\hline$<\mathrm{AQ} 1>$ & $\begin{array}{l}\text { Please confirm whether surnames/family } \\
\text { names (red) have been identified } \\
\text { correctly in the author byline. }\end{array}$ & \\
\hline$<\mathrm{AQ} 2>$ & $\begin{array}{l}\text { Please check the affiliation for } D \\
\text { correctness. }\end{array}$ & \\
\hline$<\mathrm{AQ} 3>$ & $\begin{array}{l}\text { Please chec e correspondence } \\
\text { address for correctness. }\end{array}$ & \\
\hline$<\mathrm{AQ} 4>$ & $\begin{array}{l}\text { Please check the accura } 0 \text { bf the } \\
\text { conflicts of interest statement. }\end{array}$ & \\
\hline$<\mathrm{AQ} 5>$ & Please provide manufacturere dails. & \\
\hline$<\mathrm{AQ} 6>$ & $\begin{array}{l}\text { In order to make refs. sequently } \\
\text { arranged Ref. } 25 \text { is changed to Ref. } 26 \\
\text { and vice versa. Please check and } \\
\text { approve the change. }\end{array}$ & \\
\hline$<\mathrm{AQ7}>$ & Please provide manı urer details. & \\
\hline$<\mathrm{AQ} 8>$ & $\begin{array}{l}\text { The reference "Kuchta et al. (21)" } \\
\text { replace with "Otto et al. (21)", to match } \\
\text { the author name in the reference list. }\end{array}$ & \\
\hline <AQ9> & Please cite this reference. & \\
\hline$<\mathrm{AQ} 10>$ & $\begin{array}{l}\text { Please check Acknowledg[n] nts } \\
\text { section. }\end{array}$ & \\
\hline$<\mathrm{AQ} 11>$ & $\begin{array}{l}\text { This refe } 20 \text { has been update using } \\
\text { PubMed. Please check for correctness. }\end{array}$ & \\
\hline
\end{tabular}

